\title{
ON LIQUATION AND LIQUID PHASE OXIDATION DURING LINEAR FRICTION WELDING OF NICKEL-BASE IN 738 AND CMSX 486 SUPERALLOYS
}

\author{
M. Y. Amegadzie ${ }^{1}$, O. T. Ola ${ }^{1}$, O.A. Ojo ${ }^{1}$, P. Wanjara ${ }^{2}$, and M.C. Chaturvedi ${ }^{1}$ \\ ${ }^{1}$ Department of Mechanical and Manufacturing Engineering, University of Manitoba, Winnipeg, Manitoba, R3T 5V6, Canada \\ ${ }^{2}$ National Research Council Canada, Aerospace Manufacturing Technology Centre, 5145 Ave Decelles Montréal, Québec, H3T 2B2 \\ Canada
}

Keywords: friction welding, superalloys, liquation, oxidation, compressive stress.

\begin{abstract}
A systematic study of the microstructural response of conventionally cast IN 738 and single crystal CMSX 486 superalloys during linear friction welding was performed. The results revealed that, aside from a significant liquation of various phases that occurred during joining, continuous oxide films formed on the weld lines in both materials. The weld line oxides consisted of aluminum-rich and hafnium-base oxides in IN 738 and CMSX 486 superalloys, respectively, which can be deleterious to the mechanical properties of the weld joint. Gleeble thermo-mechanical simulation showed that the oxides were produced by the oxidation of some liquid exposed to atmospheric oxygen at the mating surfaces of the work pieces. A practicable method of eliminating liquid phase oxidation during linear friction welding of nickel-base superalloys is discussed.
\end{abstract}

\section{Introduction}

Precipitation strengthened conventionally cast nickel-base superalloys, such as IN 738, are used in the manufacturing of aero and land-based gas turbine engine components due to their high temperature strength and remarkable hot corrosion resistance. Higher operating temperature demands on aero engine components have also led to an extensive use of single crystal (SX) nickel base superalloys, such as CMSX 486, which exhibit superior elevated temperature performance in comparison to their conventionally cast counterparts. Fabrication of new turbine components, as well as repair of service-damaged parts, made of conventionally cast and SX superalloys usually require joining by different welding techniques. However, IN 738, like other precipitation strengthened nickel base superalloys, is very difficult to weld due to its high susceptibility to heat-affected zone (HAZ) cracking during fusion welding processes [1, 2]. HAZ cracking in IN 738 is attributed to the liquation of various phases in the alloy, subsequent wetting of grain boundaries by the liquid and decohesion along one of the solid-liquid interfaces due to oncooling tensile stresses [2, 3]. Similarly, weldability studies performed on fusion welded CMSX 486 superalloy showed that the alloy is highly susceptible to fusion zone cracking [4]. Fusion zone cracking has also been observed in other SX nickel-base superalloys [5-7].

A recent trend in welding research involves the use of friction welding processes, such as linear friction welding (LFW), to produce crack-free welds in difficult-to-weld materials. In LFW, the heat generated by reciprocating linear motion of two work pieces against each other is utilized in plasticizing and subsequently joining them under the influence of an axial compressive forging force during the terminal stage of the process
[8]. Crack-free welding of materials by LFW was previously assumed to be a result of an exclusively solid state joining process. However, recent studies by the present authors have shown that intergranular liquation, caused by the liquation of various phases, does occur during LFW [8, 9]. Therefore, prevention of weld cracking during LFW is not due to preclusion of liquation during joining. Crack-free welding by LFW can be related to rapid re-solidification of the liquid, which is aided by the imposed compressive forging stress during welding [8] Although LFW is becoming increasingly attractive for joining nickel-base superalloys, microstructural developments in linear friction welded materials are yet to be adequately understood. The objective of this present work was to perform a systematic study of the microstructural response of conventionally cast IN 738 and single crystal CMSX 486 nickel-base superalloys during LFW, which will be useful for optimizing the welding process.

\section{Experimental Procedures}

Table I shows the chemical compositions of the as-received IN 738 and CMSX 486 superalloys. Cast IN 738 was received in the form of plates having dimensions of $240 \mathrm{~mm} \times 60 \mathrm{~mm} \times 15 \mathrm{~mm}$. Welding coupons with dimensions of $17 \mathrm{~mm} \times 12.8 \mathrm{~mm} \times 11.1$

Table I. Chemical compositions of as-received IN 738 and CMSX 486 superalloys.

\begin{tabular}{|c|c|c|}
\hline Element & IN 738 & CMSX 486 \\
\hline $\mathrm{Cr}$ & 15.84 & 5.00 \\
$\mathrm{Co}$ & 8.50 & 9.30 \\
$\mathrm{Mo}$ & 1.88 & 0.70 \\
$\mathrm{~W}$ & 2.48 & 8.60 \\
$\mathrm{Al}$ & 3.46 & 5.70 \\
$\mathrm{Ti}$ & 3.47 & 0.70 \\
$\mathrm{Zr}$ & 0.04 & 0.005 \\
$\mathrm{Hf}$ & - & 1.20 \\
$\mathrm{Re}$ & - & 3.00 \\
$\mathrm{C}$ & 0.11 & 0.07 \\
$\mathrm{Nb}$ & 0.92 & - \\
$\mathrm{Fe}$ & 0.07 & - \\
$\mathrm{Ta}$ & 1.69 & 4.50 \\
$\mathrm{~B}$ & 0.01 & 0.015 \\
$\mathrm{Ni}$ & $\mathrm{Bal}$ & $\mathrm{Bal}$ \\
\hline
\end{tabular}


mm were machined from the cast plates by using a Hansvedt model DS-2 traveling wire electro-discharge machine (EDM) and were given a pre-weld standard solution heat treatment (SHT) at $1120^{\circ} \mathrm{C}$ for 2 hours, followed by air cooling. CMSX 486 was received in form of rods having dimensions of $200 \mathrm{~mm}$ in length and $12 \mathrm{~mm}$ in diameter. Welding coupons of $17 \mathrm{~mm}$ in length were produced from these rods by sectioning the as-received material transverse to the solidification direction [001] by using wire EDM. These were then ground to produce coupons with width and thickness of $11 \mathrm{~mm}$ each. IN 738 and CMSX 486 coupons were welded separately by using a LFW process development system (PDS) at the Aerospace Manufacturing Technology Centre of the National Research Council (NRC), Canada. In this work, the oscillation frequency and amplitude were kept constant but the forging pressure was increased from a normalized value of $\mathrm{P}$ to $2.5 \mathrm{P}$ and $4 \mathrm{P}$ for selected IN 738 coupons. Gleeble thermo-mechanical simulations were also carried out by using a Gleeble 1500-D Thermo-Mechanical Simulation System in order to study and understand microstructural developments during joining. During Gleeble simulation, IN 738 and CMSX 486 materials were heated at a rapid rate of $150^{\circ} \mathrm{C}$ per second to temperatures ranging from $1150^{\circ} \mathrm{C}$ and $1350^{\circ} \mathrm{C}$. Selected IN 738 and CMSX 486 Gleeble samples were held at peak temperatures of $1270^{\circ} \mathrm{C}$ and $1275^{\circ} \mathrm{C}$, respectively, under a compressive load that was applied to achieve about $25 \%$ length reduction in 2.5 seconds, followed by air cooling.

The pre-weld, welded and Gleeble-simulated specimens were sectioned, prepared by standard metallographic techniques for microstructural examination and etched electrolytically in a 12 $\mathrm{mL} \mathrm{H}_{3} \mathrm{PO}_{4}+40 \mathrm{~mL} \mathrm{HNO}_{3}+48 \mathrm{~mL} \mathrm{H}_{2} \mathrm{SO}_{4}$ solution at 6 volts for 5 seconds. Microstructures of the specimens were analyzed by a ZEISS Axiovert 25 inverted reflected-light optical microscope equipped with a CLEMEX vision 3.0 image analyzer (Clemex Technologies Inc., Longueil, Canada), a JEOL JSM 5900 scanning electron microscope (SEM) equipped with an Oxford (Oxford Instruments, Oxford, United Kingdom) ultrathin window energy-dispersive spectrometer (EDS) and an Inca analyzing software, and a CAMECA SX 100 Electron Probe Microanalyzer.

\section{Results and Discussion}

Microstructures of Pre-Weld and Linear Friction Welded $\underline{\text { Materials }}$

The microstructure of pre-weld solution heat treated (SHT) IN 738 superalloy in Figure 1 shows a bimodal distribution of the strengthening $\gamma^{\prime}$ precipitates consisting of regular coarse primary $\gamma$ ' precipitates and fine spherical secondary $\gamma^{\prime}$ precipitates. MC carbides and $\gamma-\gamma^{\prime}$ eutectics, which usually form during casting of the alloy, were found to persist in the SHT IN 738 material. The pre-weld CMSX 486 superalloy had a directionally solidified columnar dendritic microstructure consisting of a regular distribution of ordered $\gamma$ ' precipitates with an "ogdoadically diced cube" shape (cluster of cubes [10]), as shown in Figure 2. MC carbides and $\gamma-\gamma^{\prime}$ eutectics were also distributed along the interdendritic regions of the CMSX 486 superalloy. In addition to the MC carbides and $\gamma-\gamma$ ' eutectics, a careful SEM study revealed the occurrence of a different eutectic-like hafnium-rich nickelbase phase ahead of some $\gamma-\gamma^{\prime}$ eutectics in the interdendritic regions of CMSX 486 superalloy (Figure 2). Hafnium selectively
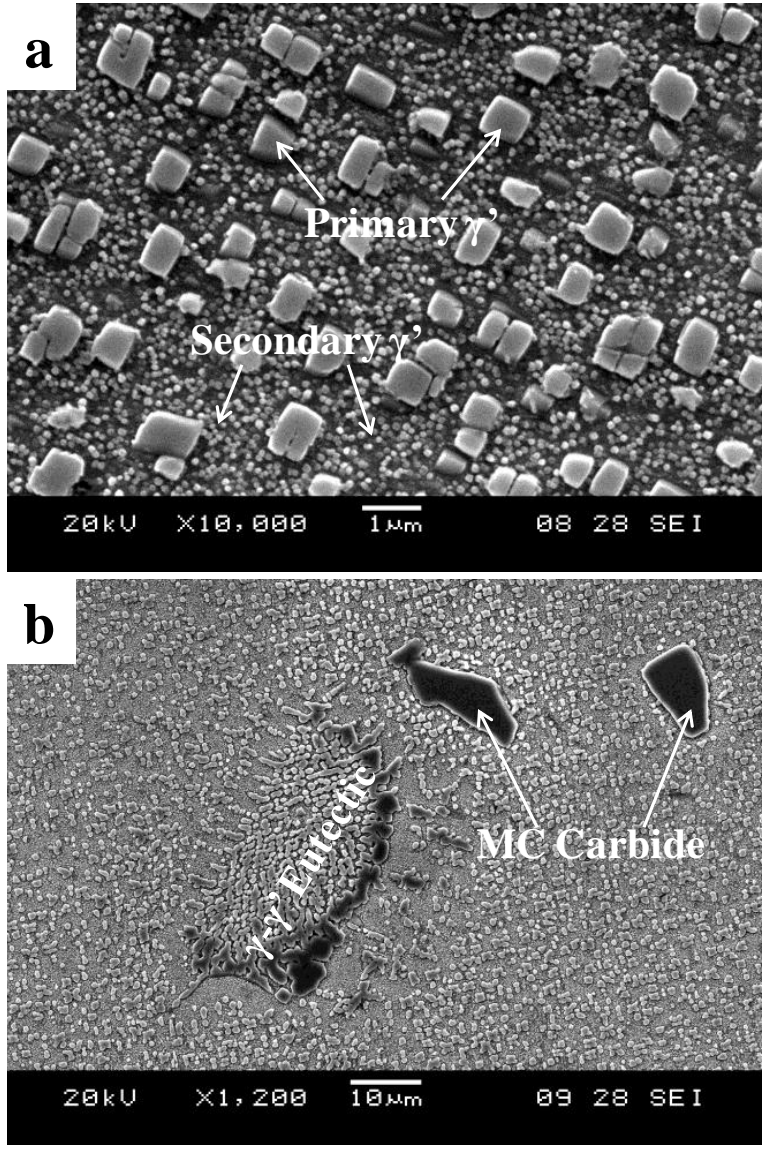

Figure 1. SEM micrographs of solution-heat-treated (SHT) IN 738 showing (a) Primary and secondary $\gamma^{\prime}$ precipitates, (b) MC carbide and $\gamma-\gamma$ ' eutectic phases.

partitions into interdendritic liquid during solidification of nickelbase superalloys, including CMSX 486 superalloy. Selective partitioning of hafnium was reported to result in the formation of nickel-hafnium intermetallic phases by eutectic-type terminal solidification reaction in front of $\gamma-\gamma^{\prime}$ eutectics in nickel-base superalloys [11, 12].

An overview of the weld joints in both IN 738 and CMSX 486 superalloys showed distinct microstructural regions across the welds, which included the weld zone (WZ) that formed at the interface between the two work pieces and the thermomechanically affected zone (TMAZ) that formed adjacent to the WZ (Figure 3). A careful SEM analysis of linear friction welds in both materials revealed that liquation of various phases occurred during joining. This liquation of phases occurred due to a nonequilibrium eutectic-type reaction of second phase particles with the matrix during the rapid thermal cycling of LFW, through a phenomenon known as constitutional liquation which was first proposed by Pepe and Savage [13]. Figure 4a is a SEM micrograph of the TMAZ of IN 738 superalloy, showing evidence of significant liquation in the welded material. The residual liquid 

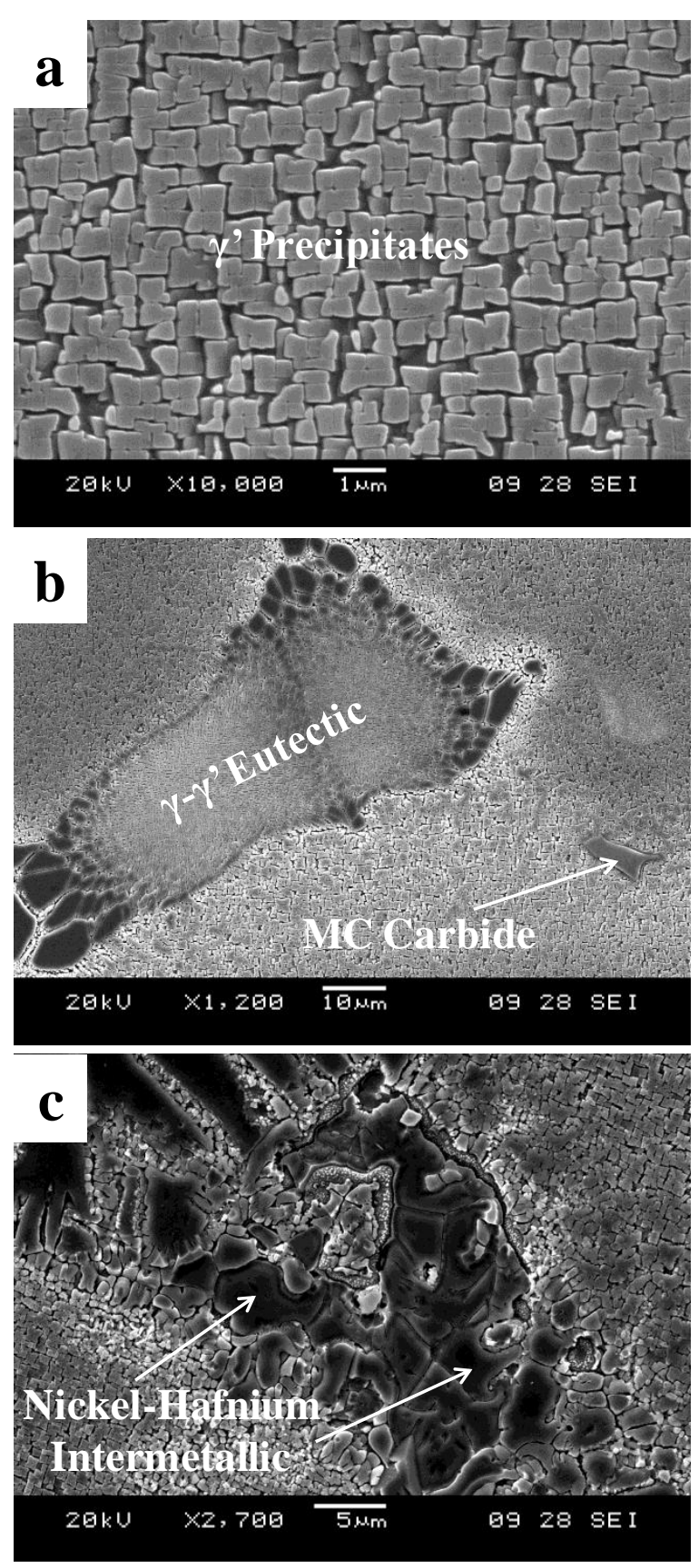

Figure 2. SEM micrograph of CMSX 486 superalloy showing (a) $\gamma$ ' precipitates, (b) MC carbide and $\gamma-\gamma$ ' eutectic phases and (c) Nickel-Hafnium intermetallic phase.

in the alloy during joining had transformed into $\gamma-\gamma^{\prime}$ eutectic products, as shown in the micrograph. Figure $4 \mathrm{~b}$ shows resolidified $\gamma-\gamma$ ' eutectic products that formed as a result of liquation in the TMAZ of the linear friction welded CMSX 486 superalloy.
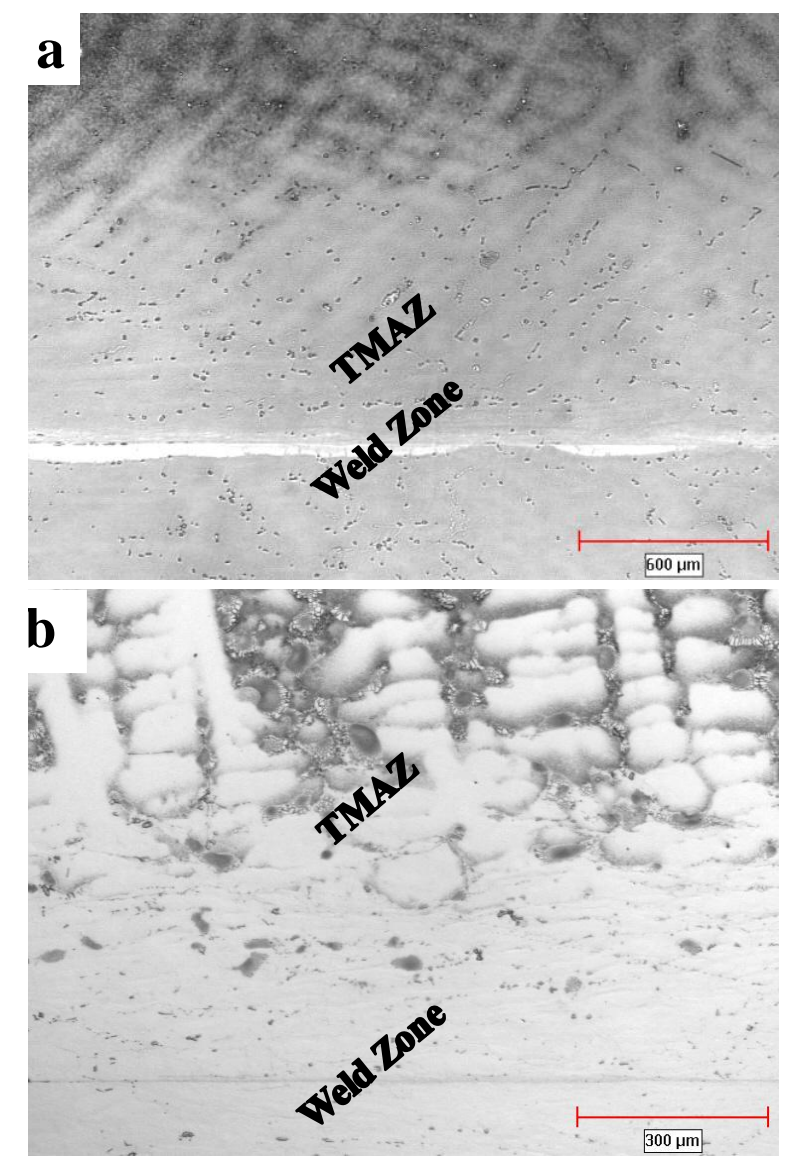

Figure 3. Optical micrographs showing an overview of the linear friction welded joint in (a) IN 738 and (b) CMSX 486 superalloys, which were welded with a forging pressure of $P$.

Additionally, the interdendritic regions, which contained the nickel-hafnium intermetallic phase, liquated and resulted in a newly formed fine eutectic product consisting of a major phase that chemically appears to be based on $\mathrm{Ni}_{5} \mathrm{Hf}$ intermetallic (Figure 4C) $[12,14]$. A detail discussion on liquation of various phases, including constitutional liquation of the strengthening $\gamma^{\prime}$ phase in IN 738 and CMSX 486 superalloys, and incipient melting of nickel-hafnium intermetallic phase to form $\gamma-\mathrm{Ni}_{5} \mathrm{Hf}$ in CMSX 486 superalloy by liquation during LFW has been provided elsewhere $[8,9]$.

Liquation occurrence in the HAZ during conventional fusion welding processes has been known to result in liquation cracking when on-cooling tensile stresses exceed the local strength at solidliquid interfaces. However, liquation cracking was not observed during LFW of IN 738 and CMSX 486 superalloys, which can be attributed to the imposed compressive stress during the forging stage of the joining process and its effect in producing straininduced rapid solidification [8,9]. Notwithstanding the straininduced rapid solidification of the liquated phases, continuous oxide phases were observed along the weld lines of both materials. The morphology and SEM-EDS spectra of these oxide phases are presented in Figure 5. Electron probe microanalysis 

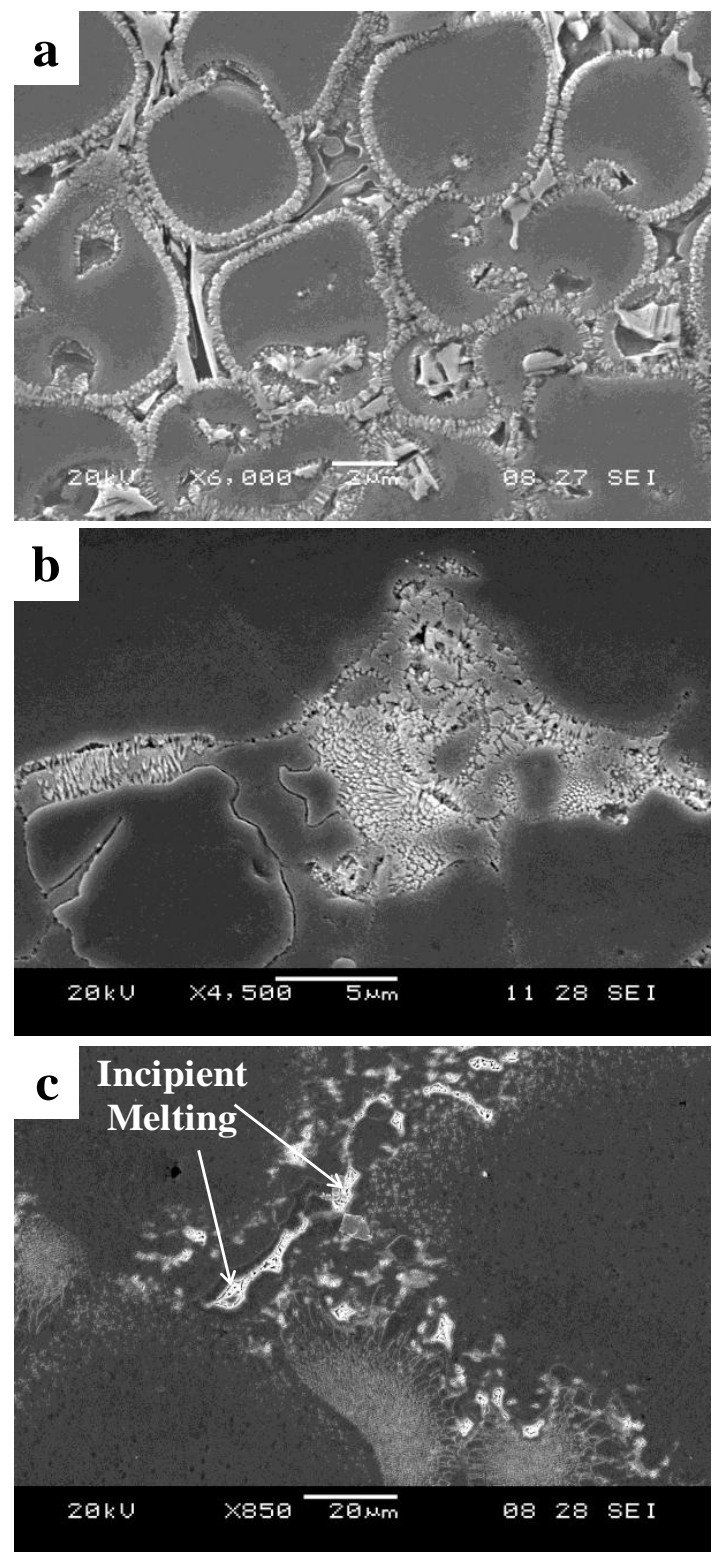

Figure 4. SEM images showing re-solidified products in the TMAZ of linear friction welded (a) IN 738 superalloy (b) CMSX 486 superalloy, and (c) incipient melting of nickel-hafnium intermetallic phase in CMSX 486 superalloy.

(EPMA) of these oxide phases revealed that a hafnium-base oxide formed on the weld line of CMSX 486 superalloy, while the oxide on the weld line of IN 738 was essentially rich in aluminum (Table II). In order to understand the formation of these continuous oxide films, the nature of oxide layers that formed on Gleeble specimens that were processed under atmospheric condition was carefully studied and this is discussed next.
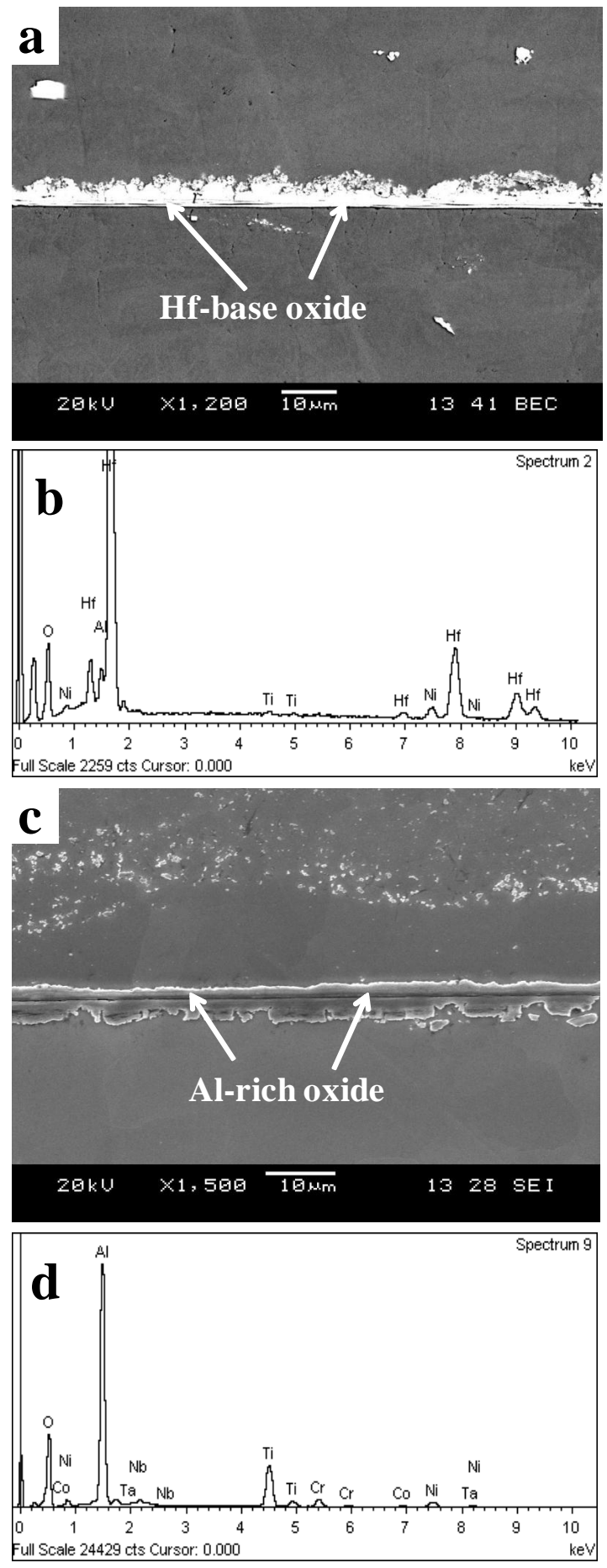

Figure 5. (a) SEM image and (b) EDS spectrum of Hf-base oxide on the weld line of CMSX 486 superalloy, and (c) SEM image and (d) EDS spectrum of Al-rich oxide on the weld line of IN 738 superalloy. The materials were welded with a forging pressure of P during LFW. 
Table II. Chemical compositions of continuous hafnium-base and aluminum-rich oxide films on the weld lines of CMSX 486 and IN 738 superalloys, respectively, determined by EPMA-WDS.

\begin{tabular}{|c|c|c|}
\hline Element & $\begin{array}{c}\text { Oxide Comp. Wt\% } \\
\text { (CMSX 486) }\end{array}$ & $\begin{array}{c}\text { Oxide Comp. Wt\% } \\
\text { (IN 738) }\end{array}$ \\
\hline $\mathrm{Cr}$ & 0.28 & 2.43 \\
$\mathrm{Co}$ & 0.72 & 0.31 \\
$\mathrm{Mo}$ & 0.03 & 0.09 \\
$\mathrm{~W}$ & 1.12 & 0.22 \\
$\mathrm{Al}$ & 2.47 & 39.03 \\
$\mathrm{Ti}$ & 0.63 & 12.82 \\
$\mathrm{Zr}$ & 0.33 & 0.06 \\
$\mathrm{Hf}$ & 76.55 & - \\
$\mathrm{Re}$ & 0.05 & - \\
$\mathrm{Nb}$ & 0.01 & 0.90 \\
$\mathrm{O}$ & 13.97 & 41.11 \\
$\mathrm{Ta}$ & 1.73 & 2.04 \\
$\mathrm{Ni}$ & 3.12 & 2.36 \\
\hline
\end{tabular}
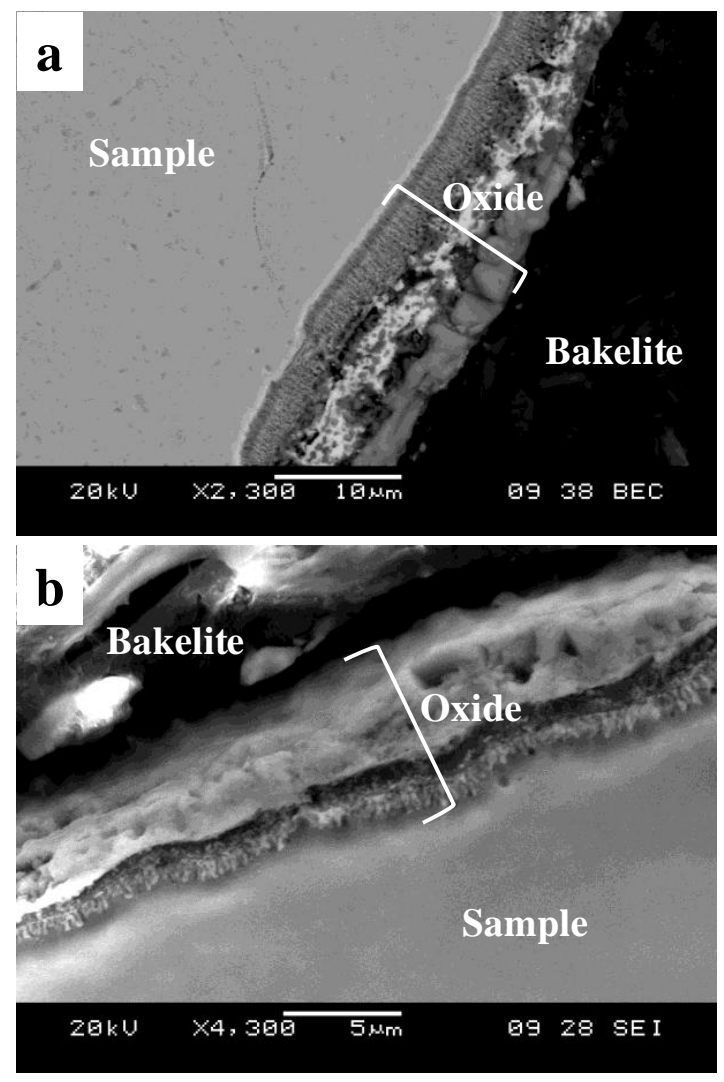

Figure 6. SEM micrographs of (a) Gleeble-simulated CMSX 486 material rapidly heated to $1275^{\circ} \mathrm{C}$ and held for $2.5 \mathrm{~s}$ (b) Gleeblesimulated IN 738 material rapidly heated to $1230^{\circ} \mathrm{C}$ and held for $2.5 \mathrm{~s}$.
Weld Line Oxidation during LFW of IN 738 and CMSX 486 Superalloys.

The formation of the hafnium-base and aluminum-rich oxides on the weld lines of CMSX 486 and IN 738, respectively, during LFW, was studied by using Gleeble simulation. Two main types of oxide scales, based on morphology and chemical composition, were observed on the Gleeble-simulated CMSX 486 and IN 738 specimens. The type 1 oxide scale in CMSX 486 specimen consisted of a nickel-based oxide outer layer and between this top layer and the substrate alloy was a mixture of different oxide phases that were rich in aluminum, chromium and nickel. Figure 6a shows an atomic-number-based backscattered electron micrograph of the morphology of the type 1 oxide in CMSX 486 superalloy. Similarly, the type 1 oxide, consisting of a mixture of different oxide phases and a nickel-base outer layer, was observed in Gleeble-simulated IN 738 superalloy (Figure 6b). The type 1 oxide scale was observed on the surfaces of all Gleeble simulated specimens. Type 1 oxide scale was also observed on CMSX-486 and IN 738 samples that were heated to $1300^{\circ} \mathrm{C}$ and $1200^{\circ} \mathrm{C}$, respectively, in an ordinary laboratory furnace and held for 5 minutes in air.

In contrast to the multi-phase oxides of the type 1 scale with different layers, the second type of oxide scale, type 2, essentially consisted of one layer of the oxide phase, which was hafniumbase in CMSX 486 and aluminum-rich in IN 738. The type 2 oxide scale was only observed in those Gleeble-simulated CMSX 486 and IN 738 specimens that experienced significant melting during rapid heating to the high peak temperatures. Examples of these types of oxides in CMSX 486 and IN 738 superalloys were observed in $1275^{\circ} \mathrm{C}$ and $1270^{\circ} \mathrm{C}$ treated specimens, respectively, where application of compressive load on the Gleeble-simulated specimens resulted in squeezing out of interdendritic liquid phase (Figures 7). In both alloys, the surfaces of the expelled liquid exposed to the atmosphere were subsequently oxidized to produce the type 2 oxide scale before the liquid became solidified (Figure 8). Similarly, at $1350^{\circ} \mathrm{C}$, where significant bulk melting occurred in CMSX 486 superalloy, type 2 oxide scale was observed on the exposed surface of melted regions, which re-solidified with a completely new dendritic microstructure (Figure 9). A similar hafnium-base oxide, suggested to be based on $\mathrm{HfO}_{2}$ and with a metallic composition that is consistent with that of the type 2 oxide scale observed in this present work, has been reported to form by oxidation of hafnium-rich liquid during casting of a hafnium-bearing nickel-base superalloy [11].

The LFW technology is generally considered as a "self-cleaning" process, where the oxides that presumably formed in the solidstate are broken down and extruded out of the joint region during the forging stage of joining [15]. However, the results of this present work revealed that the type 1 oxide scale was not observed along the weld line of the linear friction welded CMSX 486 and IN 738 superalloys. The continuous hafnium-base and aluminum-rich oxide films that formed along the weld lines were similar in morphology and composition to the type 2 oxide scales that were exclusively associated with liquation in Gleeblesimulated specimens, suggesting that the oxides at the weld line of the linear friction welded materials formed by a liquid phase reaction. As discussed earlier, liquation does occur during LFW. Some of the liquid exposed to the atmosphere at the mating surfaces of the work-pieces appeared to have reacted with oxygen 

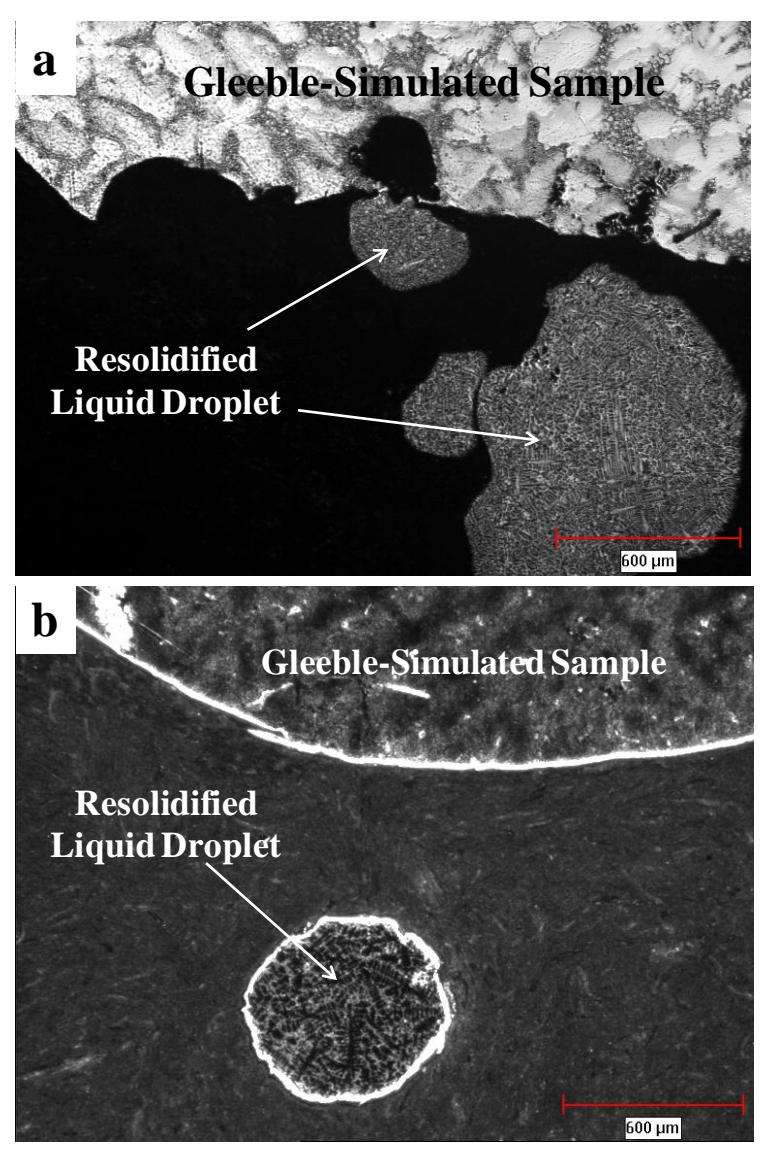

Figure 7. Optical micrographs of (a) Gleeble-simulated CMSX 486 material rapidly heated to $1275^{\circ} \mathrm{C}$ and held for $2.5 \mathrm{~s}$, with 27 percent strain a peak temperature, and (b) Gleeble-simulated IN 738 material rapidly heated to $1270^{\circ} \mathrm{C}$ and held for $2.5 \mathrm{~s}$, with 20 percent strain at peak temperature, showing re-solidified expelled liquid droplets.

to produce the continuous hafnium-base and aluminum-rich oxide films along the weld lines of CMSX 486 and IN 738 superalloys, respectively. Formation of continuous oxide films has been reported to be detrimental to the mechanical properties of nickelbase superalloys $[11,16]$. Consequently, the observed formation of continuous oxide films along the weld lines of the linear friction welded CMSX-486 and IN 738 superalloys could be detrimental to the mechanical integrity of the weld joint. Any factor that can reduce or eliminate the formation of continuous oxide films would improve the reliability of LFW for the joining of nickel-base superalloys. A practicable method of eliminating liquid phase oxidation during LFW is discussed next.

\section{Elimination of Liquid Phase Oxidation during LFW}

Microstructural developments during LFW of materials are strongly dependent on the compressive stress that is usually applied during the terminal forging stage of the welding process.
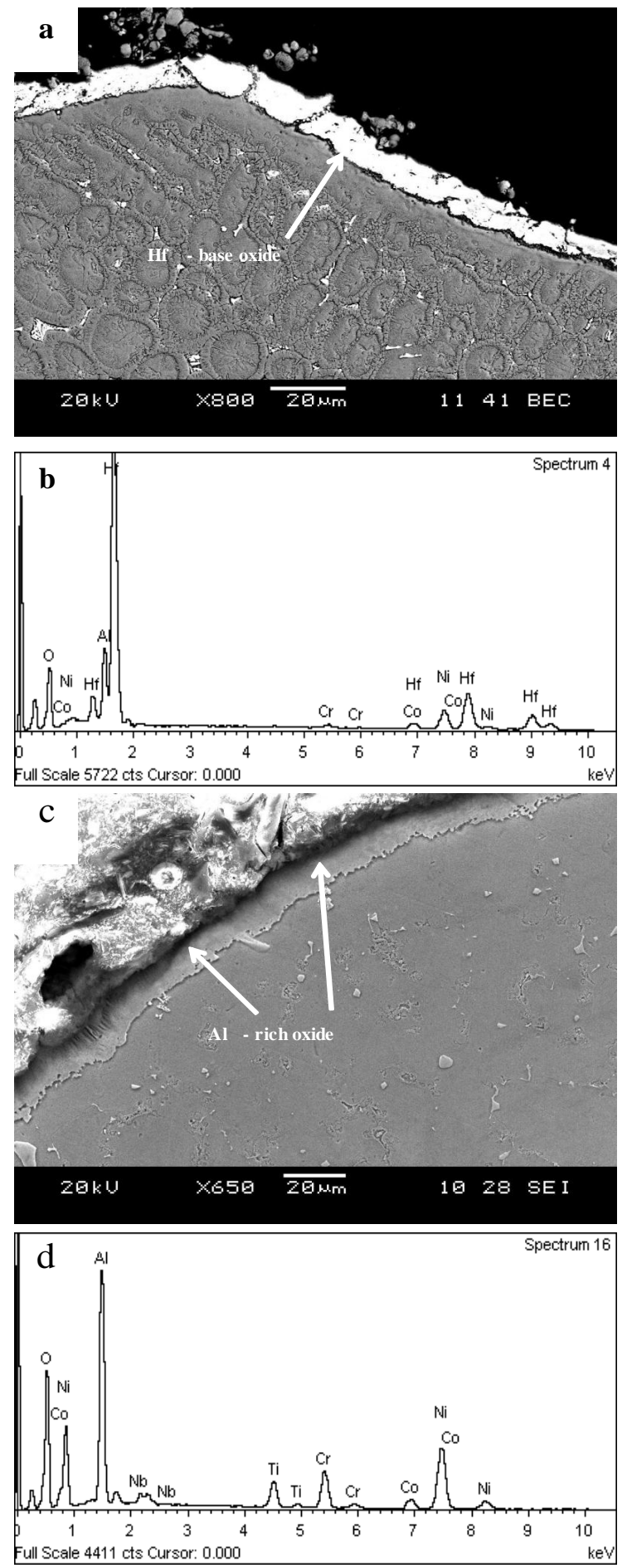

Figure 8. (a) SEM micrograph and (b) EDS spectrum of Hf-base oxide in Gleeble-simulated CMSX 486 superalloy, and (c) SEM micrograph and (d) EDS spectrum of Al-rich oxide in Gleeblesimulated IN 738 superalloy. 
The applied stress induces compressive strain in the weld joint such that the highest strain is experienced at regions closest to the weld line and decreases with distance away from the weld line. A recent study revealed that re-solidification eutectic products that formed by non-equilibrium solidification of residual liquid during cooling from welding peak temperatures were limited to the TMAZ, which is beyond $300 \mu \mathrm{m}$ away from the weld line [8]. The WZ that formed at the interface between the two welded work pieces appeared essentially free from such eutectic products. This is counterintuitive since temperature increases from the TMAZ towards the WZ, with the highest temperature existing along the weld line that separates the two welded work pieces. Accordingly, more liquation is expected to form within the $\mathrm{WZ}$ and result in a higher amount of re-solidification eutectic products compared to the TMAZ, which is what is normally observed in materials welded by conventional fusion welding processes. However, this was not the case in the linear friction welded materials. This anomalous microstructural behaviour can be related to the concept
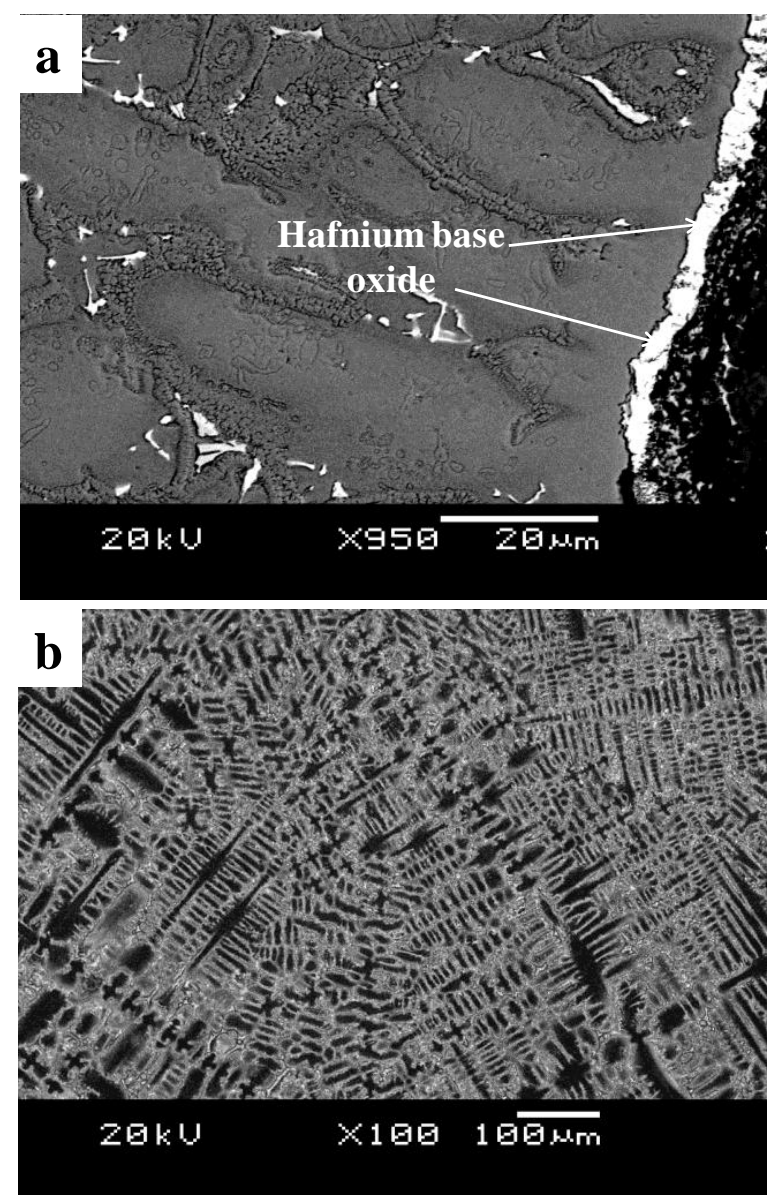

Figure 9. SEM micrographs of Gleeble-simulated CMSX 486 material rapidly heated to $1350^{\circ} \mathrm{C}$ and held for $0.5 \mathrm{~s}$, showing (a) hafnium-base oxide (backscattered electron image) and (b) a new dendritic structure. of strain-induced rapid solidification during LFW. The liquid produced in the WZ during LFW can be rapidly solidified due to the high strain experienced in this region during the forging stage, such that no residual liquid remains to be transformed into the eutectic products during cooling from the welding temperatures. The TMAZ that experienced marginal compressive strain during forging contained the re-solidification eutectic products. A detailed discussion on strain-induced rapid solidification during LFW has been reported elsewhere $[8,9]$. However, despite straininduced rapid solidification in the WZ during joining, a continuous liquid phase oxide formed by the reaction of some of the exposed liquid with atmospheric oxygen, as discussed earlier.

One possible method of removing liquid phase oxides during LFW is by increasing the compressive forging pressure, which can aid faster re-solidification of the liquid. This possibility was investigated in this present work. SEM micrographs of weld lines of linear friction welded IN 738 superalloy that were welded with
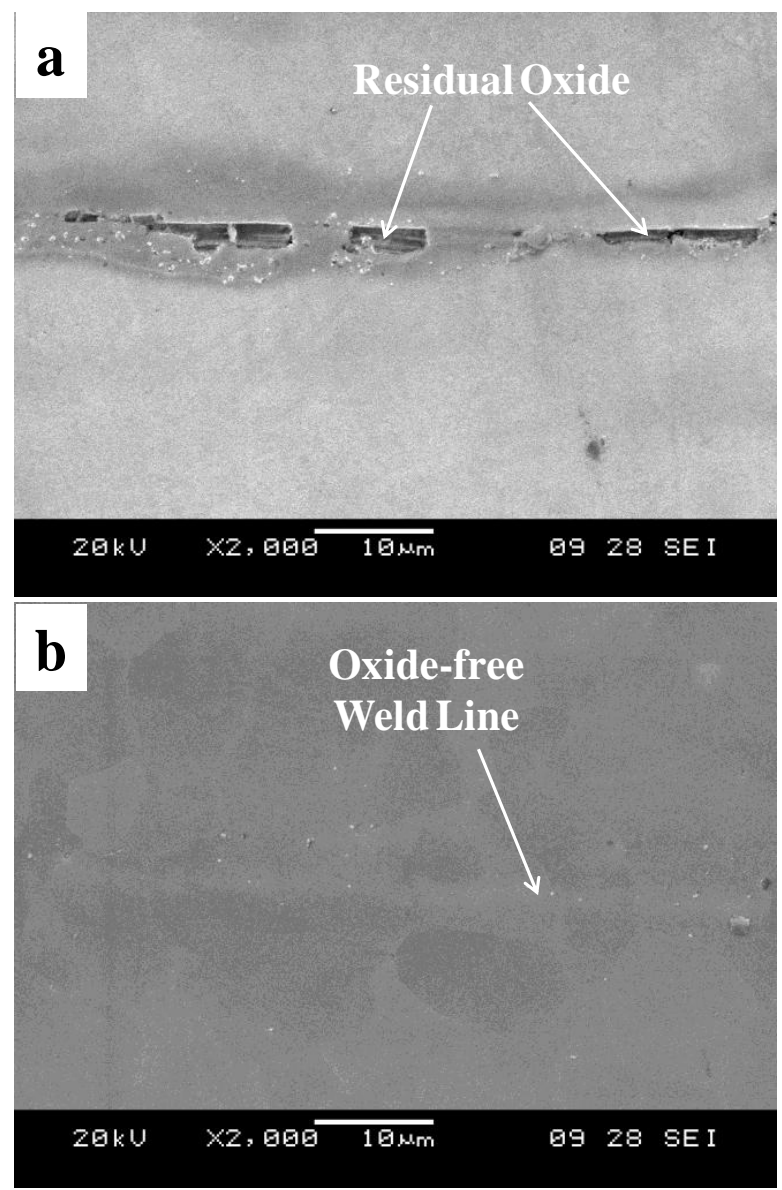

Figure 10. SEM micrographs of linear friction welded IN 738 materials, showing (a) residual oxide on the weld line of the material welded with $2.5 \mathrm{P}$ (b) oxide-free weld line in the material welded with $4 \mathrm{P}$. 
forging pressures of $2.5 \mathrm{P}$ and $4 \mathrm{P}$ are presented in Figures 10a and $10 \mathrm{~b}$, respectively. Increasing the forging pressure from $\mathrm{P}$ to $2.5 \mathrm{P}$ resulted in a significant reduction in oxidation, while the oxides were completely eliminated in the material welded with a forging pressure of 4P. The increased forging pressure produced an enhanced rapid re-solidification of the liquid, which resulted in welds that were free of oxides. Therefore, an important benefit of increasing the forging pressure during LFW is reduction in the thick and continuous weld line oxide film produced by liquid phase oxidation, which can result in improved mechanical properties of linear friction welded materials.

\section{Summary and Conclusions}

1. Significant weld line oxidation occurred during LFW of nickelbase CMSX 486 and IN 738 superalloys, which can be deleterious to the mechanical properties of the weld joints.

2. The study indicates that the oxides that formed on the weld lines were produced by the oxidation of some liquid exposed to atmospheric oxygen at the mating surfaces of the work pieces, contrary to the general assumption of exclusively solid-state oxidation during LFW.

3. Optimization of the compressive stress that was applied during the terminal forging phase of the LFW process produced an oxidefree weld line by aiding faster re-solidification of the liquid at the mating surfaces.

\section{Acknowledgement}

The authors acknowledge the financial support received from NSERC. The technical assistance of M. Guérin and E. Dalgaard for LFW of CMSX 486 and IN 738 is also greatly appreciated.

\section{References}

1. M. Prager and C. S. Shira, "Welding of Precipitation-hardening Nickel-Base Alloys,” Weld. Res. Council Bull., 128 (1968), 1-55.

2. A.T. Egbewande et al., "Improvement in Laser Weldability of Inconel 738 Superalloy through Microstructural Modification," Mater. Trans. A, 40 (2009), 2694-2704.

3. E.A. Bonifaz and N.L. Richards, "Stress-Strain Evolution in Cast IN-738 Superalloy Single Fusion Welds," International Journal of Applied Mechanics, 2 (2010), 807-826.

4. Y.L. Wang et al., "Weld Metal Cracking in Laser Beam Welded Single Crystal Nickel Base Superalloys," Mater. Sci. Technol., 25 (2009), 68-75.

5. A. Hirose et al., "Microstructure and Mechanical Property of Laser Welds of Single Crystal Nickel Base Superalloy CMSX-4," Mater. Sci. Forum, 426-432 (2003), 4007-4012.

6. S. Katayama and M. Sakamoto, "Weldability of Ni-Base Single Crystal Superalloys," ASM Conf. Proc. - Joining of and
Specialty Materials, Oct. 18-20, 2004, ASM International, Materials Park, OH, (2005), 108-112.

7. J.M. Vitek et al., " Analysis of Stray Grain Formation in Single-Crystal Nickel-Based Superalloy Welds," Superalloys 2004, TMS, Warrendale, PA, (2006), 459-465.

8. O.T. Ola et al., "Analysis of Microstructural Changes Induced by Linear Friction Welding in a Nickel-Base Superalloy," Metall. Mater. Trans. A, 42 (2011) 3761-3777.

9. O.T. Ola et al., "A Study of Linear Friction Weld Microstructure in Single Crystal CMSX-486 Superalloy," Metall. Mater. Trans. A, 43 (2012), 921-933

10. J. H. Westbrook, "Precipitation of $\mathrm{Ni}_{3} \mathrm{Al}$ from Nickel Solid Solution as Ogdoadically Diced Cubes," Zeitschrift für Kristallographie, 110 (1958), 21-29.

11. Z. Yunrong and L. Chenggong, "Skin Effect of Hf-Rich Melts and Some Aspects in its Usage for Hf-Containing Cast Nickel Superalloys," Superalloys 1988, TMS, Warrendale, PA, (1998), 475-484.

12. A. Baldan, "Electron Microprobe Investigation of Lower Melting Regions in the As-Cast Structure of DS200+Hf Single Crystal," J. Mater. Sci., 25, (1990), 4341-4348.

13. J.J. Pepe and W.F. Savage, "Effects of Constitutional Liquation in 18-Ni Maraging Steel Weldments," Weld J., 46, $1967,411 \mathrm{~s}-422 \mathrm{~s}$

14. W. Tillmann and E. Lugscheider, "Fabrication highperformance joints by solid-state diffusion bonding - A theoretical and experimental approach," International Conference on the Joining of Materials JOM-7, The European Institute for the Joining of Materials, Helsingor-Denmark, 76 (1995), pp.236-247.

15. M. E. Nunn, "Aero-Engine Improvements through Linear Friction Welding," 1st International Conference on Innovation and Integration in Aerospace Sciences. Queen's University, Belfast, Northern Ireland, UK, 2005.

16. T.M. Simpson et al., "HIP Bonding of Multiple Alloys for Advanced Disk Applications," Advanced Technologies for Superalloy Affordability, TMS, Warrendale, PA, 2000, pp.277286. 